\title{
BASTIAN (Jean-Pierre), GUICHARD (François), MESSIANT (Christine), Des protestantismes en "lusophonie catholique ", suivi de Les Protestantismes dans la cartographie religieuse au Brésil de Philippe Waniez et Violette Brunstein
}

Lusotopie, Paris, Karthala, 1998, pp. 201-420, et pp. 449-458 (bibliogr., cartes)

\section{Carmen Bernand}

\section{OpenEdition} Journals

Édition électronique

URL : http://journals.openedition.org/assr/20508

DOI : 10.4000/assr.20508

ISSN : 1777-5825

Éditeur

Éditions de l'EHESS

\section{Édition imprimée}

Date de publication : 1 juillet 2000

Pagination : $56-58$

ISBN : 2-222-96691-4

ISSN : 0335-5985

Référence électronique

Carmen Bernand, «BASTIAN (Jean-Pierre), GUICHARD (François), MESSIANT (Christine), Des protestantismes en « lusophonie catholique », suivi de Les Protestantismes dans la cartographie religieuse au Brésil de Philippe Waniez et Violette Brunstein », Archives de sciences sociales des religions [En ligne], 110 | avril-juin 2000, document 110-4, mis en ligne le 19 août 2009, consulté le 21 septembre 2020. URL : http://journals.openedition.org/assr/20508; DOI : https://doi.org/10.4000/assr.20508

Ce document a été généré automatiquement le 21 septembre 2020

(c) Archives de sciences sociales des religions 


\section{BASTIAN (Jean-Pierre), GUICHARD (François), MESSIANT (Christine), Des protestantismes en " lusophonie catholique ", suivi de Les Protestantismes dans la cartographie religieuse au Brésil de Philippe Waniez et Violette Brunstein}

Lusotopie, Paris, Karthala, 1998, pp. 201-420, et pp. 449-458 (bibliogr., cartes)

Carmen Bernand

\section{RÉFÉRENCE}

BASTIAN (Jean-Pierre), GUICHARD (François), MESSIANT (Christine)

Des protestantismes en "lusophonie catholique ", suivi de Les Protestantismes dans la cartographie religieuse au Brésil de Philippe Waniez et Violette Brunstein. Lusotopie, Paris, Karthala, 1998, pp. 201-420, et pp. 449-458 (bibliogr., cartes)

Spécialisée dans le monde lusophone, la revue Lusotopie présente un important dossier en deux parties (dont la seconde devait paraître en 1999) sur les protestantismes dans les pays lusophones (Brésil, Portugal, Angola, Sao Tomé, Mozambique) dont l'avantage est d'offrir une vue comparative des différents courants englobés dans le terme générique de " protestantisme ». Ces espaces ont en commun une histoire, marquée par les migrations et la culture portugaises, et une langue de communication, le portugais. Communs également à l'ensemble du champ lusophone sont la position marginale du 
protestantisme et les changements survenus à l'époque contemporaine avec la fin du monopole de l'Église catholique et l'essor de la diversité religieuse.

2 Une mise au point des concepts sociologiques précède l'étude concrète de cas. L'éclo sion des courants protestants en Amérique latine, par exemple, remet en cause les trois aspects de la modernité : rationalité, différenciation et autonomie de la personne. En effet, la religion en Amérique latine est créatrice d'identités collectives nouvelles et ne s'accompagne pas forcément $d u$ processus d'individualisation. Les minorités protestantes en lusophonie sont des minorités actives, dans le sens donné par P. Moscovici à cette expression. Perçus comme des sectes, les protestantismes divers s'avèrent en fait des agents actifs de recomposition religieuse.

Comme J.-P.B. le rappelle, c'est au Brésil que l'on trouve aujourd'hui une communauté protestante représentant $15 \%$ de la population, la plus importante du monde après celle des États-Unis. Mais l'objet "protestantisme » est problématique dans les pays lusophones et l'auteur en dégage six formes idéal-typiques dont le courant dominant, d'un point de vue numérique, est le pentecôtisme sous sa forme charismatique. Les mouvements religieux protestants sont nombreux dans les marges, qu'elles soient géographiques, sociales ou culturelles. L'imaginaire pentecôtiste se construit sur la libre interprétation des textes bibliques et sur les récits de miracles et de guérisons propres à la société pentecôtiste et à son dirigeant charismatique. Il faut noter que dans le cas des pentecôtismes lusophones, le discours n'est pas régulé par les théologiens ce qui conduit à la multiplication des expressions particulières concurrentes, et au déplacement du fidèle de groupe en groupe en quête d'une meilleure efficacité pour résoudre ses préoccupations concernant l'amour, l'argent et la santé, les trois invariants qui sous-tendent toute démarche religieuse. J.-P.B. insiste sur des phénomènes de sortie de la marginalité à travers la représentation politique des Églises, la visibilité médiatique des pratiques et la transnationalisation des sociétés religieuses. Les protestantismes dans la cartographie brésilienne montrent que le pentecôtisme a le plus d'adeptes non pas dans les villes mais dans les régions frontalières agricoles ou minières, là où le rapport de masculinité est élevé. Succès rencontré par cette confession dans l'urbanisation et dans les frontières pionnières, où elle apparaît plus structurante.

4 En Afrique portugaise, les premiers messagers du protestantisme furent des missionnaires étrangers, qui "colonisèrent l'imaginaire» des populations, suivant l'expression de Serge Gruzinski : dressage des corps, techniques d'intériorisation de l'autorité, du pouvoir, des formes d'organisation, des symboles et allégories. Pour C.M., missionnaires catholiques et protestants partagent une même vision de l'Africain comme sauvage. Mais leur attitude à l'égard des religions africaines n'a pas été constante au fil des décennies. Dans les territoires africains, les protestantismes ne constituent pas des marges géographiques ni des périphéries par rapport à un centre catholique. Les missions protestantes sont au cœur de la colonie. Elles ont été les foyers d'émergence du nationalisme moderne.

5 Les missionnaires protestants ont-ils été plus progressistes que les catholiques? C'est en tout cas l'opinion simplificatrice du FRELIMO (Front de Libération du Mozambique). L'article d'Éric Morier-Genoud introduit des nuances mais malgré ces précisions, les liens entre certaines élites, les luttes anticoloniales et le protestantisme semblent avérés. L'intérêt des articles sur l'Afrique réside justement dans ces rapports entre confessions et anticolonialisme, entre les tentatives de «portugalisation» des 
indigènes et les influences étrangères, donc non portugaises, à travers les missions protestantes mais aussi catholiques. Car l'engouement américain et canadien pour le travail missionnaire s'est accru durant le XIX ${ }^{\mathrm{e}}$ siècle tandis qu'à la fin de cette période, le manque de vocations au Portugal a eu pour conséquence l'introduction en Afrique de missionnaires catholiques d'origine étrangère, qui ne pouvaient pas mener à bien comme leurs confrères lusitains, la "portugalisation » des indigènes. Didier Péclard explique qu'en 1965, la plupart des fidèles protestants des hauts-plateaux de l'Angola s'étaient définis comme américains dans un recensement. Il montre que les protestants, en choisissant d'installer leurs missions loin des villes et des bourgades, créant ainsi un territoire "protégé » de la décadence urbaine, ont favorisé les références identitaires " africaines », tandis que leurs rivaux catholiques, voués à l'assimilation des Angolais, ont plutôt privilégié « la construction du sujet ».

6 En 1959, l'État colonial et catholique tente un dernier effort pour contrôler les dissidences religieuses et, par la même occasion, contenir les mouvements anticolonialistes, en favorisant la diversité religieuse. Témoins de Jéhovah, anglicans et élites musulmanes sont accueillis dans le dessein de favoriser les divergences religieuses et d'affaiblir la contestation politique. Peine perdue car les dynamiques religieuses favorisèrent à court terme l'anticolonialisme. En somme, le lecteur trouvera dans ce recueil des descriptions très fouillées de cas et de situations permettant de mieux comprendre les liens entre la politique coloniale et anticoloniale, les courants religieux, la formation des élites et l'émergence de l'ethnicité. 